\title{
Studio on Beauty: A new Methodology for Digital Design Research
}

\author{
Sabri Gokmen \\ Georgia Institute of Technology, USA \\ sabrigokmen@gatech.edu
}

\begin{abstract}
In this paper we present a studio framework that connects Ruskin's conception of beauty and digital design tools. We define eight different aspects of beauty that are studied via natural and artificial patterns. These studies developed by students are later applied to a site and program in the second half of the studio. Some of the works of the students are presented while narrating the overall pedagogical process. The aim of the paper is to present a unique approach that combines theory on beauty with digital tools in order to re-define design research as an open-ended and dynamic practice.
\end{abstract}

Keywords: Beauty, Digital design pedagogy, Ruskin

\section{Introduction}

The integration of digital technologies has been influential on the design pedagogy for the past twenty years affecting the means of research and production (Giddings et.al. 2008, Reffat, 2007). This changing paradigm is being defined as in need of a new methodological approach that integrates digital technologies into the process of education (Oxman, 2006). In contemporary thinking about design education, there has been a tendency from looking at certain types of forms towards one in diagrams. While the former reduces the ambiguity of design process to focus on a formalist outcome, the latter tends to be more generative and define different avenues for how design could be carried. In this sense, diagrams should not be understood as schemata of forms, but organizational depictions which try to understand the stability of type as much as their variability (Spuybroek, 2004). In this paper a contemporary application of this process oriented pedagogy will be introduced, focusing on digital design research and beauty. The studio scope was set by Lars Spuybroek to examine John Ruskin's notion of "vital beauty" and define research topics to be investigated using digital tools (Spuybroek, 2011). The studio pedagogy was applied to the fourth year undergraduate studio at School of Architecture in Georgia Institute of Technology. In this paper the studio approach and topics will be discussed while showing some of the examples of student work.

\section{Ruskin's Vital Beauty}

Towards the end of the twentieth century, beauty became more suspect in the aesthetics of art and architecture. Since the beginning of the digital paradigm words like fracture, process, abstraction, deconstruction, fragment, purity became common descriptors that influenced certain styles of architecture and means of form making. These expressions are usually in opposition to beauty, but relate to the sublime instead (Spuybroek, 2011). Generally those who advocate a return of "real" beauty have a classical aesthetic sense. This formalist notion means an interest in the harmony, proportions and unity in design that is applied holistically to a system. In this studio, the focus is not on these classical values, but rather on Ruskin's notion of "vital beauty," a beauty of imperfection, fragility and variation (Ruskin, 1892). Vital beauty is based on active parts that strive for beautiful compositions by means of interaction and collaboration. These components are not balanced or at rest, but participating, entangling and constructing. These characteristics make the onlooker a participant as well, engaging with beauty by agency.

\section{Aspects of Beauty}

For the study of beauty Lars Spuybroek defined eight different research tracks that could be studied through natural and artificial (man-made) patterns. These aspects of beauty are: roughness, imperfection, opulence, grace, incandescence, veiling, fragility and smoothness. While these aspects offer a different quality of beauty, they often follow rule based and computable systems that will be later utilized for various design processes (Figure 1). A further explanation of these aspects will follow.

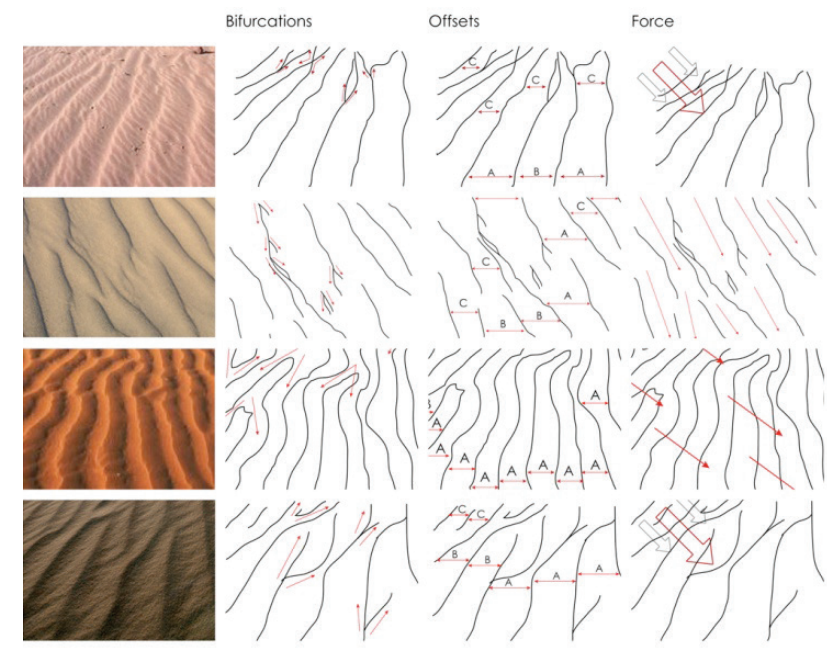

Figure 1: Sand dunes. Analysis showing inherent rules of organization. Students: Alyssa McKay, Rebecca Duncan, Instructors: L. Spuybroek, S.Gokmen. 

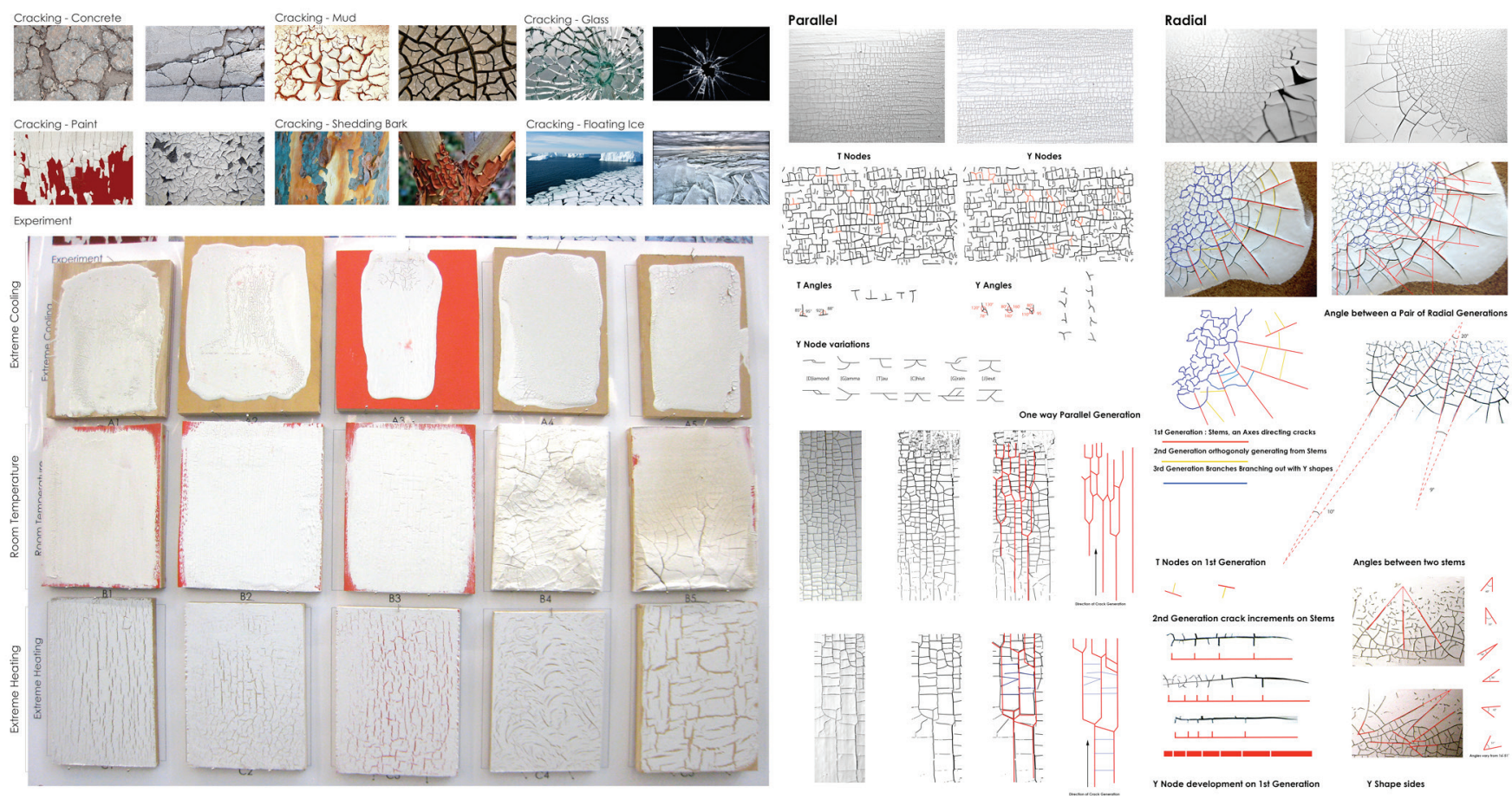

Figure 2: Mud cracking Diagrams. The students start by compiling images for the study of patterns. Then they created various material studies to analyze how cracking patterns work by using paint and heat. Students: Almir Divanovic, Hrach Burtoyan. Instructors: L. Spuybroek, S.Gokmen

Roughness is about fractal like geometries that can be found in coast outlines, rock formations and mountains (Ball, 1999). Following Ruskin's admiration of the mountain Matterhorn, this aspect is closely related to the textured appearance of broken surfaces that are extruted by vertical deviations. As a formative concept, roughness relates to sharp, edgy or broken geometries that follow specific frequencies.

Imperfection is related to patterns formed by non-standardized parts that allow mistakes or errors. Mud-cracking and dry stone walls are imperfect systems, where the irregularity of parts is compensated by the inherent patterning of the overall system that follows certain rule sets (Figure 2). African tribal art, like the Shoowa-Kuba tapestries, also produces imperfect patterns where geometric lines break when multiple patterns are joined together (Gokmen, 2012).

Opulence considers the rich and abundant use of an element to become a principle of organization. For instance, people at the park occupy space by maintaining a certain distance towards others as they cluster. Industrial paintings of Laurence Stephen Lowry also show similar effects where the people are depicted as variations of "matchstick men" that aggregate to form crowds.

Grace is affiliated to elegance where the quality of movement or the balance of a posture conveys the simplicity and consistency of a composition. In many ancient Greek sculptures we can find graceful forms through the placement of limbs or the orientation of the body. Grace can also express itself through dancing where the coordinated flow of limbs engages with the onlooker.
Incandescence is defined as the emission of visible light from a source due to increased intensity or higher temperature. The most important aspect of an incandescent object is that it contains a physical body and a radiating light effect. When things glow, they create visual patterns that generate increased dimensionality for the perception of the object.

Veiling is the concept of hiding or covering of form to express certain qualities while highlighting others. In Renaissance sculptures veiling is often used to enhance the underlying body parts of a depicted human figure. Although veil requires a body to be placed upon, it can also create various folding patterns due to the internal structuring of the cloth.

Fragility is the structuring of weak parts that are individually susceptible to break. Tomatillo husks, spider webs or butterfly wings are examples of this category where forms are a result of the agency of very thin elements. However, the networking among these parts adds further strength to the overall intricate structure creating light and permeable systems.

Smoothness is the opposite of roughness, where the overall geometries are rounded and the aggregation of parts yield to selforganizing systems. Sand dunes and water waves follow this type of character where wind forces guide the accumulation of material deposits that yield to the patterning of smooth surfaces (Figure 1).

The eight aspects of beauty all share similar qualities and characteristics while they differ in terms of how the agency of parts work towards form. Since these systems follow rigorous 
rules and principles, they could be studied in a procedural fashion using computation. During this process computational tools are only used to complement the notion of beauty that is studied through research, rather than limiting the outcomes of the studio to the norms of the tools that are used. In order to accomplish such methodology beauty is first studied through the agency of parts by mapping the interaction, bundling, overlapping, intersection and joining. These operations yield to material and structural outcomes that can be further analyzed, diagrammed and then developed in a digital design curriculum. In the following part we will be showing how this process is carried in a digital design studio framework.

\section{Digital Design Pedagogy}

The studio pedagogy is divided into two main sections that spans over sixteen weeks. During the first half of eight weeks, groups of students research different topics of beauty through collecting images and diagramming. The research begins as teamwork between two students, but the actual design is done by individuals in the second half of the studio. While the first phase is founded on beauty from which techniques of design are distilled, the second phase focuses on the application of these techniques to a building typology, site and program (Baerlecken, 2012). The purpose of the investigation is to define beauty not by mere inspiration and subjectivity but through methods and techniques that could be replicated using digital tools (Spuybroek, 2009, Spuybroek, 2011).

\section{Digital Patterns: Natural and artificial patterns and techniques}

The digital design studio started by looking at each aspect of beauty through a set of images to study the agency of parts. The student groups found various examples of natural patterns and artificial techniques to extract information on how the beauty works in a part-to-whole process. Prior to diagramming the student groups work on rearranging these images with different patterns based on parametric evaluations of a system.

In the diagramming phase, the students look at the inner structuring of these patterns to extract variable figures and their configurational qualities. Initially students start by looking at images and classifying how their topic could create different products under different conditions. For instance, the group that studied imperfection looked at various cracking patterns, such as mud, paint, ice and glass, to understand the variation among different cracking types. The goal of this part is to define the variability of a system through the activity and variation of parts. Using diagrams, figural variations as well as configurational behaviors under different conditions and parameters were mapped for further research (Figure 2).

\section{Generative diagrams}

While the initial diagrams followed a schematic tracing of images to extract existing patterns, the latter phase focused on creating dynamic and generative diagrams that can create new patterns with changing inputs and control (Garcia, 2010). At first the diagrams were manipulated from flat matrices into a set of threedimensional patterns. These studies were further developed into digital modeling strategies to create various surface topologies and massing methods prior to any information about site or program. At this stage students used Rhino modeling and scripting tools to develop models that can generate their patterns in three dimensional configurations. The overall intention was to construct a digital machine that is configurable by the architect before it is transformed to fit into a specific architectural need (Spuybroek, 2004).

After mid-term, the diagrams of beauty were applied to an urban city block. During the progression of the studio, consistency maintains an important position. The generative diagrams do not form a portion of the architecture but inform all elements of design. At this stage it was evident that the digital models that are developed by the students limited the application of their systems. Some of the generated patterns related to surface treatment, while others related to massing or structuring of a system. But the main goal is to study how the three could be merged within the domain of architectural design to achieve a unified understanding of beauty. As a result, the final designs aimed at satisfying both aesthetic qualities and structural properties that inform architectural organization.

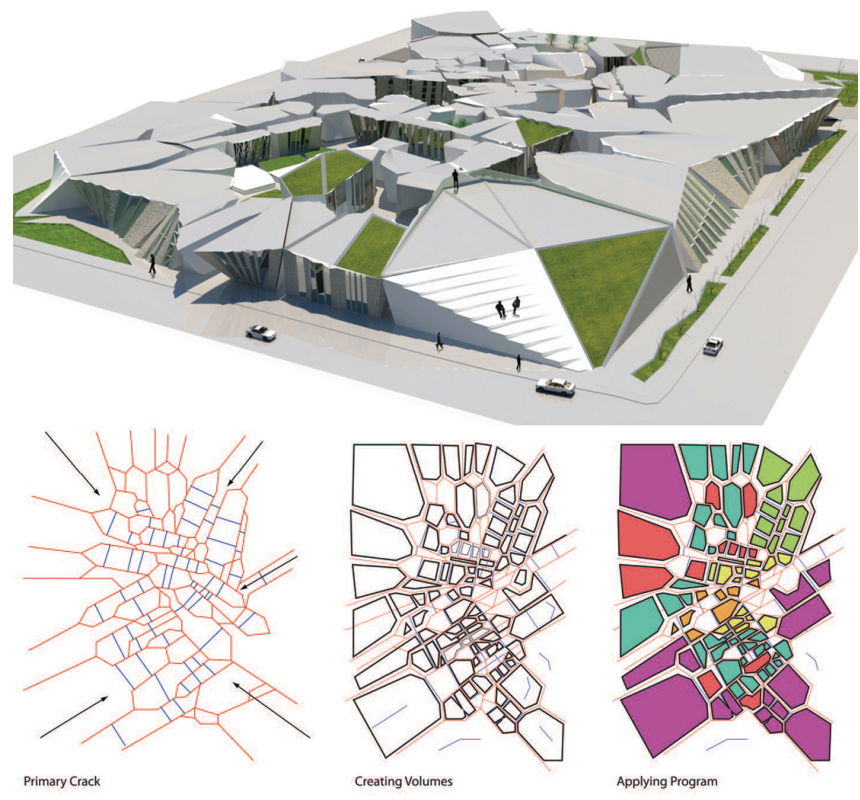

Figure 3. Imperfection. Student: Almir Divanovic, Instructors: L. Spuybroek, S.Gokmen.

\section{Case Studies}

In this part we will be presenting some projects of students to show how this methodology is applied following the design pedagogy of the studio. Each of the projects will feature a different aspect of beauty and how it is instrumentalized towards the case of architectural design. 


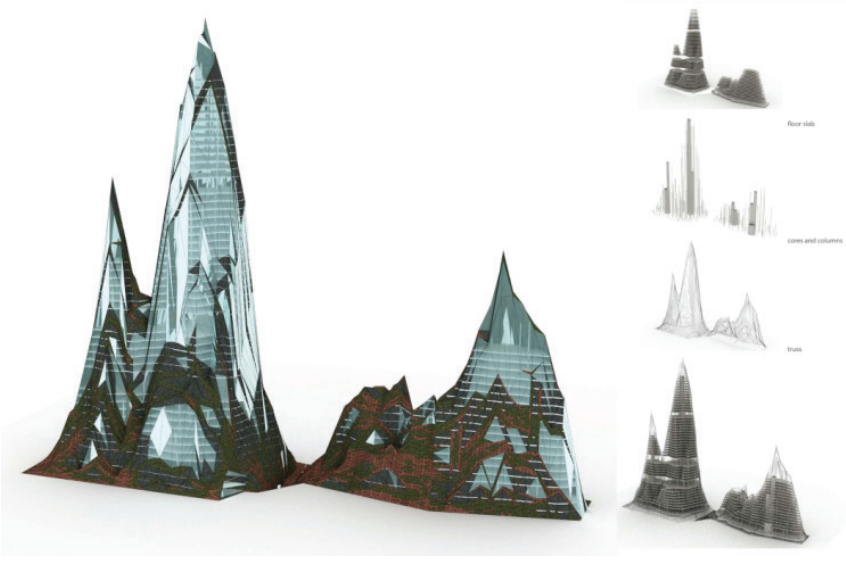

Figure 4: Roughness. Student: Seon Ji Yi, Instructors: L. Spuybroek, S.Gokmen

\section{Imperfection: Mud cracking}

The following project started by looking at mud cracking as a system of imperfection that can inform three dimensional massing studies. During the research phase the student group prepared various material experiments to study the variation of cracking under different heating and material properties using paint (Figure 2 ). These studies were further diagrammed and mapped with parameters to be later implemented as a master planning tool. In the second half of the studio, the student chose a rehabilitation center program and used the mud cracking technique to subdivide the site into different program components and create street networks. The patterns were applied three dimensionally to reorganize the program distribution and articulate the overall massing through subdivision (Figure 3).

\section{Roughness: Mountains}

This project started by looking at fractal geometries that appear in nature that can create peaking outlines. The student studied various mountain formations and outlines as an expression of the inner fracturing and eruption of subterranean forces. Using an algorithm, the student was able to create variations of mountain outlines by changing parameters of fractal division and eruption. In the second half, she used the approach to create three dimensional massing studies that followed assembled silhouette schemas. Using the outlines as inputs, the student designed forms with local peaks and ridges that are suitable for a multi-use urban block (Figure 4).

\section{Fragility: Train tracks}

The following research started by looking at fragile networking structures that bring thinner elements into larger networks. The student group analyzed river beds, train tracks and highways while diagramming the formative qualities and rule sets of individual curvilinear figures. These studies were later used as a structural networking system that was developed into a tower project (Figure 5). The student chose an urban block and applied three dimensional compositions of elements that followed parameters extracted from train track systems.

\section{Opulence: People at the park}

This study focused on the spatial distribution and clusters of people at the park as a way to generate three dimensional organizations that can create a rich and articulated effect. The student studied the logic and parameters of packing systems using analog computing. Then she used the approach to generate volumetric units that can be spatially organized following the initial rule sets and operations. Using various housing program units, the design was executed both on a micro level, organizing the inner grouping of rooms in a house; and on the macro level, where the three dimensional packing of different housing units created an urban housing block (Figure 6).
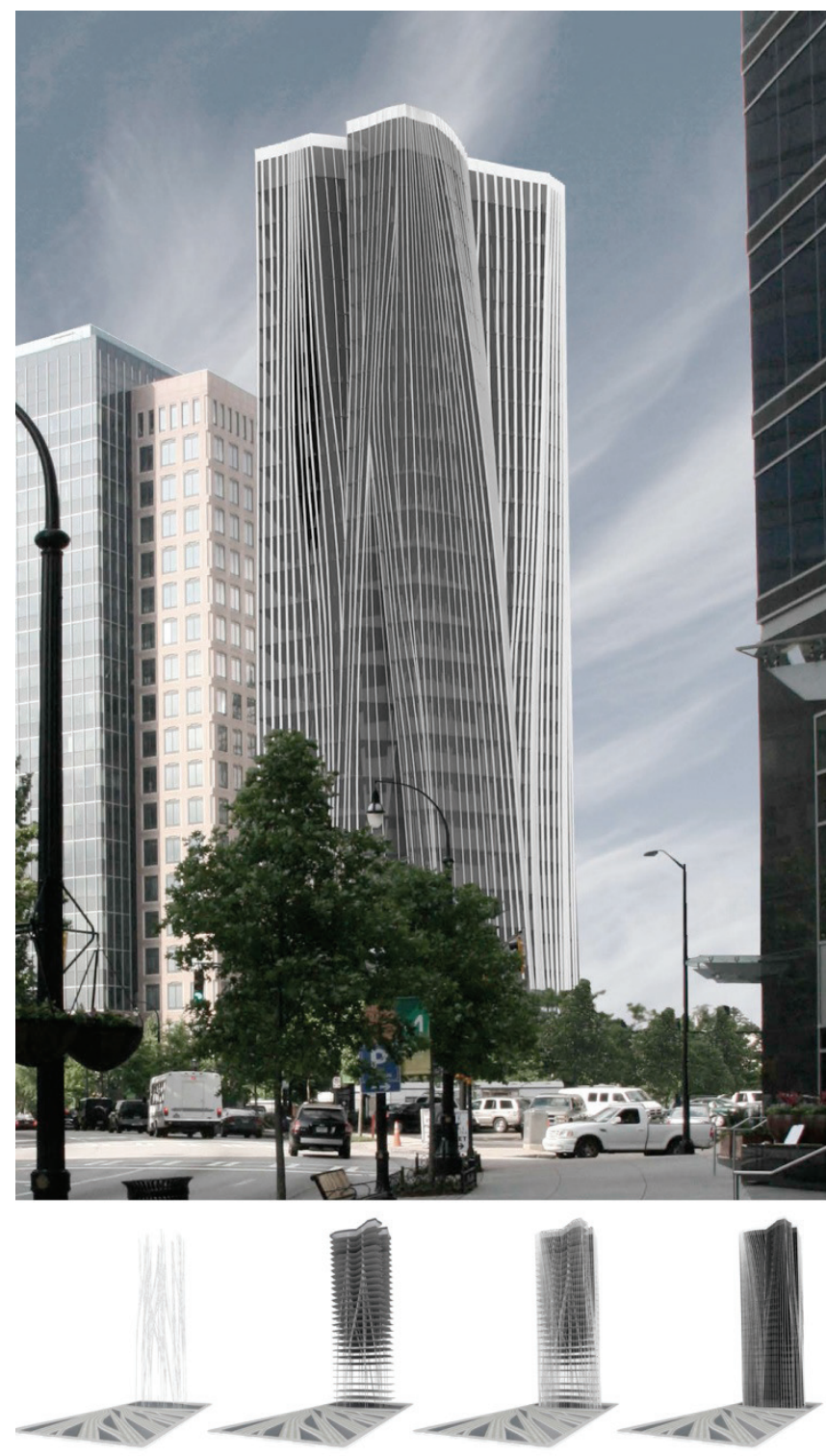

Figure 5: Fragility, Student: Ralf Iberle, Instructors: L. Spuybroek, S.Gokmen 

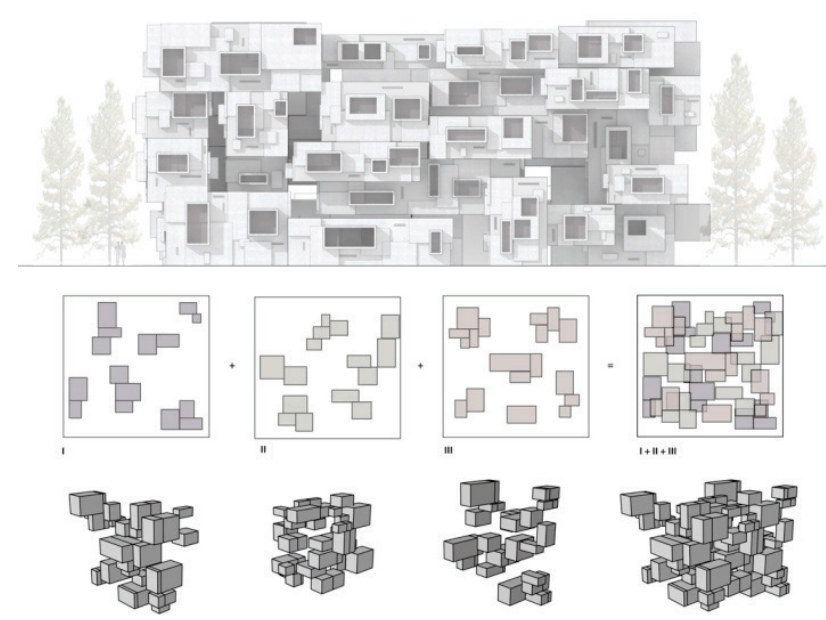

Figure 6: Opulence, Student: Yeun Kim, Instructors: L. Spuybroek, S.Gokmen

\section{Conclusion}

In this paper we presented a unique approach for contemporary design pedagogy that combines theory and digital tools. Looking at Ruskin's ideas about beauty has been fruitful to reconsider the digital paradigm, and repurpose some of the parametric tools to guide the methods and techniques (Terzidis, 2007). In this sense computation followed the notion of beauty which is studied via natural and artificial techniques leading the methodology towards various generative design outcomes. We believe that the knowledge and experience produced out of the studio could help educate a new breed of architects that can combine aesthetics and digital modeling.

During the studio the main struggle has been to present the reverse methodology to the students where the site and program was introduced in the second half of the curriculum. Although this created an initial surprise among the students, soon they adapted to focus on studying patterns and developing an understanding for digital and analog techniques. From a pedagogical point of view, this aspect liberates the learning outcomes from a standardized studio structure by helping students to learn diagramming, digital modeling, representation techniques and computation. In our case the study of beauty received positive feedbacks from both the students and the jury that stirred discussion for the use of technology and revival of beauty in current digital paradigm.

\section{References}

Baerlecken, D., Riether, G. (2012). Aggregates: Digital design for design, Proceedings of the $17^{\text {th }}$ International Conference on Computer Aided Architectural Design Research in Asia / Chennai 25-28 April 2012, pp.607-616.

Ball, P. (1999). The Self-Made Tapestry: Pattern formation in nature, Oxford University Press, Oxford (England).

Giddings, B., Horne, M. (2008). The changing patterns of architectural design education in the UK, In: First International Conference on Critical Digital: What matter(s)?, 18 - 19 April 2008, Havard University Graduate School of Design, Cambridge, MA ,USA.

Gokmen, S. (2012). The Ornaments of Shoowa Kuba: A digital reinterpretation of a textile art, SIGraDi 2012 [Proceedings of the $16^{\text {th }}$ Iberoamerican Congress of Digital Graphics] Brasil - Fortaleza 13- 16 November 2012, pp.79-83.

Oxman, R. (2006). Theory and design in the first digital age," Design studies. 27 , no. 3, 229-265.

Reffat, R., (2007). Revitalizing architectural design studio teaching using ICT: Reflections on practical implementations," International Journal of Education and Development using Information and Communication Technology (IJEDICT), Vol. 3, Issue 1, pp. 39-53.

Ruskin, J. (1892). The Nature of Gothic: A Chapter of The Stones of Venice. Printed at the Kelmscott Press, Hammersmith, and published by George Allen, London, 1892.

Spuybroek, L. (2004). Nox: Machining architecture, New York, N.Y. ,Thames \& Hudson.

Spuybroek, L. (2009). Research\& Design: the architecture of variation, New York: Thames \& Hudson.

Spuybroek, L. (2011). Research\& Design: textile tectonics, Rotterdam : NAi Publishers.

Spuybroek, L. (2011). The Sympathy of Things: Ruskin and the Ecology of Design, Rotterdam: V2 Publishing.

Terzidis, K. (2007). Digital Design: Ideological Gap or Paradigm Shift?, SIGraDi 2007 - [Proceedings of the 11th Iberoamerican Congress of Digital Graphics] Mexico D.F. - Mexico 23-25 October 2007, pp. 220224. 